\title{
TOOLS FOR BRIDGING THE CULTURES OF EVERYDAY AND SCIENTIFIC THINKING
}

\author{
JAN HAWKINS and ROY D. PEA \\ Center for Children and Technology, Bank Street College of Education
}

\begin{abstract}
A perspective about science education is developed which has implications for the design of interactive learning technologies. Current philosophical work concerning the interpretative nature of scientific inquiry is reviewed as a context for discussing the situation of the child in developing scientific understanding. This view of learning emphasizes the relationships among informal understanding, conceptual change, and enculturation into modes of scientific discourse. A prototype software system for supporting scientific inquiry processes in students is described.
\end{abstract}

\section{Introduction}

We develop in this article a perspective which underlies an approach to creating new technology-based supports for science learning. In previous decades, one aspect of science curricula reform focussed on the need to give students understanding and experience with the actual practices of professional science (Bredderman, 1983; Jackson, 1983; Shymansky, 1983). The aim was to extend science learning beyond the acquisition of textbook facts to the methods and procedures of scientific investigation. We extend this line of argument to incorporate implications for science education of what Frederick Ferre has called the "postmodern" critique of the nature of scientific knowing. Basically, this shift has involved replacing the idea of scientist as detached observer to that of participant, in which scientists shape, not only document, their objects of study. As Toulmin (1982) describes it, "in postmodern science nature is no longer held at arm's length"' (p. 106).

We also consider the child's situation in developing scientific competence as presenting a problem not simply of being instructed in new concepts or methods, but of being asked to engage in a complex process of modifying "natural" notions about empirical phenomenon, and being initiated into thinking and talking in terms of the standards of explanation of the scientific community and in relation to its problems. While cognitive studies of how students' preconceptions interplay with formal science education have focused on the 
conceptual change problem, the latter sociocultural and discourse dimensions of science education have been underemphasized. Our analysis culminates in a generative perspective on the difficulties of students and teachers in science education. We then sketch the implications of our perspective for designing learning technologies by means of an example of a software system developed to support inquiry practices in science classrooms.

Recent historical and philosophical analyses of scientific processes have developed arguments that understanding and progress in science is best viewed as constructed knowledge within communities of knowers rather than descriptive of a reality mirrored through particular human procedures (e.g. KnorrCetina, 1981; Rorty, 1979). The consequence is that scientific progress is not viewed as a smooth cumulative process, but as revisionary within communities of scholars (e.g., Taylor, 1980; Toulmin, 1972, 1982), or more radically as revolutionary changes in dominant paradigms occasioned by new approaches to problems found intractable or anomalous given current conceptions (Feyerabend, 1975, 1978; Kuhn, 1962, 1977; Lakatos, 1976).

These arguments have been necessitated by detailed historical analyses of the development of scientific knowledge and conceptual change, and by descriptive accounts of how scientific work is actually conducted in laboratories (e.g. Goodfield, 1982; Knorr-Cetina, 1981) and among scholars in particular fields (e.g. Geertz 1983). These arguments have also been considerably influenced by deconstructionist and hermeneutic perspectives on the critical interpretation of texts, in which human interpretation is shown to be constituted by existing traditions, interests, and social practices, and marked by historicity, fallibility, and finitude (Bernstein, 1986; also see Black, 1954; Foucalt, 1980; Gadamer, 1981; Habermas, 1981; MacIntyre, 1981; Rorty, 1982).

These developments among others suggest that scientific knowledge is critical interpretation, not deductive generalization from the "facts" of observation (Hacking, 1985; Toulmin, 1982). They have in common the notion that explanatory systems in science are multiple (cf., Chaiklin, 1986; Geertz, 1983; Stevens \& Collins, 1980; Toulmin, 1982), and that styles of interpretation change. In Toulmin's view, "the choice of a basic theory or conceptual scheme-a choice made in light of experience, to be sure, but never imposed by it-precedes the formulation of those scientific questions to which any specific explanation is a possible answer (1982, p. 110)."

Different factors have been proposed as bearing on the nature of these choices. For example, some analyse emphasize the social-historical context as a shaper of interpretative understanding (Knorr-Cetina, 1981) and as a source for selecting and legitimizing what is taken to be true, or the boundaries of what may be entertained as possible (Hacking, 1985). Others emphasize the tendencies of individual scientists for particular types of explanatory systems (Schwab, 1960) or "root metaphors" which generate possible connections within a conceptual system (e.g. Pepper, 1942). These may be more or less influenced by the larger social framework in which the interpretive work is historically embedded. An interpretative and revisionary rather than cumulative view of scientific progress thus has the implication that "cultural" processes (variously defined) influence what are taken to be problems, even what "styles of reason- 
ing'" apply (Hacking, 1985), and how authority for the status of knowledge can be assigned and justified.

The search for solutions to the problem of selecting and justifying knowledge in the face of a looming relativism in which all knowledge claims are created equal occupies the center stage of today's philosophy of science as it seeks to understand the nature of the scientific enterprise (e.g., Bernstein, 1983; Gadamer, 1981; Rorty, 1979; Taylor, 1980). Without resolving these issues, we can nonetheless trace implications of these current understandings of scientific knowledge and progress for elementary and secondary science.

As part of the science-learning agenda in schools, students need to explore and teachers to support inquiry practices that reveal science as a distinctively human way of approaching and understanding natural phenomena. In addition to learning scientific practice as embodied in the "scientific method" which characterizes canonical science, students need to develop understanding of the nature of scientific knowledge and the interpretative process of scientific inquiry. This is not solely textbook-based knowledge, but knowledge developed through experience with particular kinds of critical thinking practices. Students need to expand their views of science to include not only questions of fact ("what is true about this?"), but questions of the form, "what can we make of this?" (Toulmin, 1982). The purpose-relative nature of truth claims in science now seen as central in the philosophy of science can thus be brought into the classroom.

In an historical analysis of the development and impact of federal programs for revising science education in the last two decades, Duschl (1985) suggests that the revolution in historical and philosophical understanding of the nature of science that was going on at the time did not find its way into the programs. He argues that the scientists who largely had control of these developments offered an inadequate version of the nature of inquiry. Research suggests (Herron, 1971) that true inquiry activities are rare in classrooms, even where teachers have been trained to use materials labelled as "inquiry-oriented." Revisions in science education should enable teachers and students to focus on the new ways of understanding science rather than yet more refined approaches to the accumulation of facts or canned methods: "The concept of making science education an inquiry into inquiry was and still is a viable idea" (Duschl, 1985, p. 548).

The second element of our perspective concerns the child's place in relation to this formidable edifice of scientific information, and complex practices that have evolved for constructing scientific understanding: "The apprentice scientist masters the current interpretive standpoint of a science in the course of being enculturated into the professional community of that science" (Toulmin, 1982, p. 98). Such a cultural practice perspective on science education has profound implications.

We formulate here a conception of the process of science education, and briefly explore three core notions:

1. Children construct knowledge structures for science understanding on a domain by domain basis prior to formal schooling. Attempts by teachers to 
teach canonical science meet conceptual barriers in the informal explanations of natural phenomena that have "worked" (been sufficiently adaptive) for students thus far (e.g., Clement, 1986b; diSessa, 1983, in press). Such "preconceptions" have been documented in many areas of science education (West \& Pines, 1985).

2. In science education as in the history of science (Toulmin, 1972), conceptual change in scientific thinking may be described as emerging from evolutionary adaptation of existing conceptual structures to the "problem niches" to which such thinking is applied;

3. Science learning is a process of socialization into a professional community, with its canonical problem niches, standards of explanation, and modes of discourse for communal sense-making. This is a complex sociocultural process that is not sufficiently captured in the traditional practices of science instruction.

\section{Developmental Construction of Knowledge}

There has been a consensus building on the importance of viewing the child as actively constructing knowledge through interactions with the physical and sociocultural environment, perhaps most influentially presented by Piaget. Some versions of the constructive view of development emphasize the local nature of constructed knowledge in particular domains or circumstances, and the influence of the cultural surround (Laboratory of Comparative Human Cognition, 1983; Vygotsky, 1978).

Even as toddlers, children engage in the epistemic activity of asking for and giving explanatory accounts of why things are the way they are (Bullock, Gelman, \& Baillargeon, 1982; Carey, 1985; Gelman, Spelke, \& Meck, 1983; Hood \& Bloom, 1979; Shultz, 1982). One functional reason for developing these explanations is to have more predictive control over one's world: to avoid unfortunate events and perpetuate fortunate ones. The child comes to know what to expect to happen as initiated by self, others, and by event contingencies of the natural world. Children thus construct understandings of natural phenomena as they encounter them, as well as frames for interpreting the meaning of natural and social events (Nelson \& Gruendel, 1981). Beliefs and explanations are built from children's direct experience of events and from such accounts as their culture offers for why things are as they are. These accounts depend in large part on the cultural setting surrounding the childobjects and events, people, media, informal learning situations, and the practices of such institutions as schools.

In school, whether recognized as such or not by teachers, children are active interpretative learners who bring their prior understandings and frames of interpretation to making sense of pedagogical presentations and interchanges, and other events occurring in this learning setting. "Understanding", may be an extremely complex phenomenon involving thousands of "facts," strategies, and conditions for applying knowledge (Simon, 1981). The extensive literature that has developed concerning student misconceptions from canonical physics attests to the complexity of the preformal knowledge students construct in this domain (e.g., Clement, 1982; diSessa, 1982; Halloun \& Hes- 
tenes, 1985; McDermott, 1984; White, 1983). Describing the state of such understanding as a coherent model or theoretical system may fall short of capturing this complexity (diSessa, in press). Furthermore, attention in the novice-expert literature on scientific reasoning has been directed primarily to individual cognition, not to the scientific communication conventions that give rise to these understandings and afford the possibilities of their further revision in light of new problems, data, uses of thinking tools, or conceptual schemes proposed by others.

As active learners, understanding develops by motivated engagement with issues that the learner feels to be genuinely problematic (Dewey, 1933). Deep understanding does not simply arise from acquiring new information, but from relinquishing or reconfiguring some other way of conceiving a phenomena (Bruner, 1962). In the context of mathematical discovery, Lakatos (1976) discusses the resilience of existing conceptual schemes to contradiction, and studies in developmental psychology and science education have made little progress to date in defining conditions for effective provision of contradictions in promoting conceptual development (e.g., Clement, 1986b; Posner et al., 1982), although some evidence indicates that when the conflict arises from the child's own contradictory judgements rather than an authority's, progressive conceptual change occurs (Snyder \& Feldman, 1977; Stavy \& Berkowitz, 1980; Strauss, in press; Strauss \& Ilan, 1977). Schools can thus present alternative views to the child or explanations that contradict the child's preconceptions (diSessa, 1982; Linn, 1983), but need to take seriously the task of supporting the child's struggles to adopt new perspectives or integrate new ideas with such explanations as he or she already believes.

\section{Problem Niches}

"Science" education is defined broadly to include science, mathematics, and technology education. Roughly, "scientific" concepts and problem-solving methods are those technical concepts and methods used in scientific communication and to structure scientific inquiries that are but rarely spontaneously developed (Vygotsky, 1962). They typically depend on formal education for transmission. The scope of science education appears as a moving edge, with continual refreshment from the developing sciences. Frontier discoveries a few decades ago constitute routine science material today.

Science has always been defined by the problems it works on, in the strong sense that its frontiers consist of problems not yet posed by any scientist. One way in which scientific thinking differs from everyday thinking is that their problem niches differ dramatically. The notion of "niche" is borrowed from biological theory, where it defines the ecological space in which organisms adapt and survive. Just as physical features or behaviors are adaptive or not in an ecological niche, conceptual schemes and styles of reasoning are adaptive or not in a problem niche. And just as ecological niches are shaped in part by the species that struggle within them, so are problem niches continually redefined by the minds that struggle within them and at their boundaries in order to understand. The notion of problem niche allows us to capture the basic idea that what is taken to be problematic differs for the "cultures" of everyday 
thinking and formal science. For example, metaphors that suffice to "make sense" for communal agreement in everyday problem-solving niches may break down when analyzed closely for the coherencies, robustness, and noncontradictoriness demanded in scientific discourse (diSessa, 1986a). But what everyday and formal scientific thinking do have in common is the essential bridge between them: the concept of explanation.

\section{Explanations}

We have highlighted how it is common for even toddlers to call for and offer explanations of natural phenomena as part of their interaction with the natural world. How do plants grow? Why does dew form? Why do balloons rise only with some gases? Why is a clap louder if one's hands are cupped? Why did the car overheat? Why do you see your breath on a cold day (Collins, 1986)? Such questions are asked (at least outside the classroom) when the questionner's concepts are insufficiently developed to generalize to understanding the present case, and the questionner is motivated to further understand.

"Accountings" for such phenomena are common in everyday conversation. One feature of explanatory accounts, whether in everyday conversation or science, is that they each have a certain precision. An explanation is expressed with some degree of exactitude, with the tacit assumption that the explanation is sufficient for the purposes for which the inquirer asked the question. We will call this purpose-relative feature of explanations its pragmatic precision. ${ }^{1}$ An explanatory account suffices for the inquirer if it is precise enough - in terms of qualitative and quantitative features-for the purposes of inquiry. "Suffice" is a socially constructed normative standard, subject to change and adaptation. If an explanation is not sufficiently precise for the norms of the commmunity or purpose of the questionner, then dialogue and often, additional inquiry, may take place to help refine it. This developmental process is a constructive one, with social inputs from a community of other inquirers. For example, in typical conversation the appropriate precision of an answer to the question about what time it is typically does not involve nanoseconds, because 'it doesn't matter"'. But this statement is truncated; in its full form, it reads: "it doesn't matter for the purpose for which I asked the question". For comparing the speed of execution for two different computer program routines for space shuttle guidance systems, it may be essential data.

Similarly, definitions of variables, the range of variables considered, and the acknowledged interactions among variables that are appropriate for consideration in particular explanatory accounts will vary with purpose, as any experience in building simulation models demonstrates. For example, it is important to consider surface tension in some inquiries which invoke Archimede's principle (e.g., studying water insect locomotion), but not in others where less precision suffices (e.g., determining lead weight gradations needed for sea diving by humans).

\footnotetext{
${ }^{1}$ The term for this concept is due to Seth Chaiklin. The concept is at least tacit in the "cultural practices" view of cross-cultural cognition offered by the Laboratory of Comparative Human Cognition (1983), and in current work on everyday mathematical thinking by Lave (1986; also see Lave et al., 1984).
} 
The notion of explanatory precision interacts with the notion of problem niche. Each "culture" or community has a set of problems that serves to bound the types of problems considered at a particular time (which can be transformed by extraordinary individuals, or circumstances such as crises or technological innovation). There is a tacit limit of precision for explanations judged as acceptable by a specific community of inquirers that is directly tied to the state of a problem niche. Thinking and explanation is adaptive to the circumstances to which it is directed. Changes in the problem niche may change the requirements for sufficient precision as former conceptual schemes become incapable of covering more challenging problem situations. New situations may render problematic that which was not so before, or require new methods. Exploration of uses for new technologies may provide opportunities to rethink problems one could even possibly solve (e.g., supercomputers and weather control; or artificial intelligence techniques for rapid VLSI circuit design). The fine motion control required in robotics for automated factories has, for example, engendered the creation of new mathematics and science. Problems of life-threatening dioxins from burning toxic wastes, the need to analyze the impact of acid rain on deforestation, and better prediction of earthquakes, all test the limits of simulation modelling for complex environmental systems.

The broad and comprehensive nature of the problem niches of the scientific community has evolved, domain by domain, over a sustained period of deliberate problem-solving and explanation-seeking. Special general techniques-the scientific method, the use of statistics, formal models, mathematical formalisms, new artificial intelligence languages for representing human knowledge and expertise, and other communal tools-have been developed for establishing the utility of different explanatory accounts of natural phenomena. Special concepts, such as temperature, force, and correlation, have been defined. The explanations offered by the natural sciences are often orders of magnitude more precise than the explanations offered in everyday life. They are more precise because the erotetic purposes of scientists in their problem niches demand such precision.

\section{The Culture of Science and Science Education}

There are features of the scientific community and its educational agents, teachers, which make the metaphor of science "cultures" useful. As in crosscultural processes of understanding, challenges arise for making sense of why people of a foreign culture do what they do. The teacher and the student each have a complex induction task to face: how to make sense of the explanations that each offers for natural phenomena. "Tuning' what the student takes to be problematic and the newly required pragmatic precision of explanations from the student's current point of view to the canonical standards of science is the primary pedagogical aim. Learning new concepts and thinking methods are but part of the process, not the final goal.

A major hypothesis of this framework is that explicit recognition of the cross-cultural nature of science education has rich and unexpected implications for improving its theories and practices. The framework makes sensible new orientations to students' difficulties, because it leads to examination of new 
contributory factors and different pathways out of the problem of science difficulties. The cross-cultural nature of what is taken to be "problematic" and what is considered "explanatory" among teachers and students is not often observed as an important source of educational problems. And the shifting epistemic status of scientific knowledge claims as a function of purpose, which we have argued is commensurate with current understandings of the historical construction of scientific knowledge, is rarely treated in science education at all. Science education tends to present science as a body of knowledge composed of established facts and methods.

In science education part of what the child must learn are the conventions that will make the discourse of science sensible. A major part of this discourse for scientific thinking and reasoning is recognizing problems and being able to offer explanations in terms of formal concepts that meet communal norms. Part of developing explanations is learning how to engage in a process of inquiry that is "scientific," and which incorporates communally-accepted warrants for beliefs or knowledge claims. Inquiry practices in science involve a host of subskills, such as question identification, development and revision; hypothetical and counterfactual thinking; isolation of variables; systematic observation and measurement; identifying trends in data and other forms of statistical reasoning; recognizing what constitutes evidence; and construction of models and arguments to communicate knowledge claims to others.

When the two "cultures" meet, the problem is one of creating conditions for compelling conceptual change, to impel the child to adapt his or her understanding to deal with the new explanatory standards of the problem niches of the communities of science. The child must induce that his or her explanations are inadequate in terms of precision, completeness, coherence from the perspective of canonical science. This is not to say they are "wrong," for the language game of science is a new one (Ryle, 1954). And some of the old ideas work, in that some intuitions from everyday thinking are integral to scientific conceptions (such as the idea that a pushed spring exerts force: Clement, 1986a; diSessa, 1982). To guide preformal understandings to reconstructed new ones in science will involve providing materials and pedagogical moves (coaching, support, demonstration, hints, examples) that are sufficient to enable the child to construct explanations from the perspective of the science teacher's culture. There must also be some pedagogical framework for helping the child to recognize that the effort of learning, of becoming sufficiently involved in this culture to reorder one's explanations, is worth the cost. Perceived cognitive effort of learning to use new thinking strategies and ideas is likely to be a deciding factor in whether they are acquired at all.

These processes of understanding are generally tacit in both directionsfrom teacher to child and child to teacher-and are not seen as part of the goal structure within which teaching-learning interactions take place. Thus, it often happens that what is "learned" by students is taken on only at the surfacelevel, and coexists with the children's deeper understanding from their own “culture"' (e.g., diSessa, 1986a). The child can perform for tests but not apply this "learning" to real problems outside the framework of textbook chapters. The outcome of science learning can thus exist as a set of inert ideas that are not generative, nor interactive with the explanations children have constructed 
themselves (and with the help of others outside schooling) for natural phenomena. One has to "live" in the culture and be accountable in one's explanations to the normative standards of one's community in order to deeply understand.

\section{Technology}

We have been concerned with inventing possible roles for software in developing an approach to science education congruent with this "cross-cultural" perspective. As computer technologies become widely available in science classrooms, we believe it is important to develop a software system that incorporates recent understandings of the nature of scientific knowledge and science learning into the ways that inquiry activities are structured. Design of technologies for science education need to be informed by an image of what is worth knowing in an information society, not only as better delivery vehicles for traditional science materials. Our work is based on the conviction that in addition to helping students engage in using the methods of working scientists (a key element of precollege science curriculum reform in the past two decades), science education should generate awareness of the nature of scientific knowledge and inquiry, and take seriously the difficulties students and teachers face in decentering from the boundaries of their explanations of natural phenomena from their respective "cultures."

One way of thinking about the design of technological systems emphasizes their potential as reorganizers of mental functioning (Pea, 1985). The way systems organize activities can have the effect of redefining educational goals and the cognitive tasks required to attain them. Prototype systems need to be created in light of this potential for redefinition, and their effects then systematically studied (Hawkins, Mawby, \& Ghitman, in press; Pea, 1985).

Our prior analysis of the nature of some key difficulties in science education leads us to think about designs which take advantage of the dynamic capacities of information technologies to help students reflect on their own ideas and problems, and to support students in juxtaposing the web of the ideas held in their "culture" with information from the cultures of science. The goal of the enterprise is to help students to make problematic their own assumptions, and to begin to help them to develop a deeper understanding of how explanations and scientific formalisms are coherent and efficient means for grasping a broad range of phenomena.

Furthermore, system design must build on the fact that science education takes place predominantly in the complex social circumstances of classrooms. Building bridges between the conceptual understandings of teachers and students is a highly individualized enterprise, yet the organization of classroom learning has tended to make this sort of complex and personalized interaction difficult to sustain. Technologies can be designed to help address this problem.

\section{Structuring the Process}

Norman (1986) argues that there is a gulf to be bridged between persons and technological systems. The design of interfaces for computer-based tools should offer the user control over variables of psychological interest. Norman 
makes no commitment about what these variables are or should be in any context. The types of interactions demanded by the system will come to color the way people think about both the system and the task. The system should also enhance rather than prevent creative exploration of ideas or materials (diSessa, 1986).

In developmental terms, this approach to system design has some similarities with Vygotsky's (1978) theory of the processes underlying children's knowledge development. Adults collaborate with children in getting tasks done, and in the process "scaffold" children's learning in ways that reveal the structure of a task and supplement children's developing abilities to accomplish the task. As children continue to participate in learning situations, they increasingly take over parts of the process. Recent work on the developmental psychology of reading and writing has found this approach to be productive in education (e.g., Applebee \& Langer, 1983; Palincsar \& Brown, 1984; Scardamalia \& Bereiter, 1985).

In developing technological supports for helping children to learn new skills it is important to structure the interface in such a way that the enterprise is understandable and accessible to them in their present state of knowledge. It should progressively reveal the structure of the cognitive task even as it supports its accomplishment.

We begin with the belief that students need to learn about and practice scientific inquiry in such a way that they learn to develop questions and problems, recognize their own ideas and knowledge-states, learn to explore the consequences of alternative ideas (from other "cultures"), and juxtapose and try out integrations of this new information with their own beliefs. As part of this enterprise they necessarily encounter different ways of rendering a situation, issue, or idea problematic.

The INQUIRE software system $w^{2}$ are developing is designed to be modular, and has the following features to support a structure for inquiry processes:

(1) A "Questions" module helps students to identify and specify their own questions about a problem region, and to examine their own state of knowledge with respect to the problem and the questions they generate about it. Features of the module enable students to reflectively examine this material (e.g., by rating their degree of belief certainty about it; by using a categorization system for trying out different organizations of the questions and material they create) before they begin to encounter "new" information from observations, experimentation, or reading. The module helps students to construct a plan for their inquiry, which acts as a summary "blackboard" for reminding them of their top-level ideas and questions, and which is transported throughout the system as the student works. Guidance through reminders of place in complex tasks appear to be useful for users of complex interfaces (e.g., Miyata \& Norman, 1986) and for novices doing complex tasks (Glynn et al., 1982; Scarmadalia \& Bereiter, 1985; Schoenfeld, 1985).

${ }^{2}$ The "we" behind the Inquire Project includes Cornelia Brunner, Seth Chaiklin, Marie Ghitman, Frankie Mann, and Babette Moeller. 
"Cognitive blackboards" of this sort appear as an interesting feature of expert inquiry. People construct top-level (mental or on-paper) guides to remind them of the major issues and questions as they work through new material. Such monitoring supports act to prevent side-tracking (Hawkins et al., in press), and may be revised as inquiry proceeds.

(2) A "Notes" module helps students to record, manage and analyze new information they find in texts, communications with people, and observations and experiments which might be performed in the laboratory or through using computer simulations. The tool is organized so that students must record the source and context of information. It enables them to easily record and flexibly store notes-both material found in texts and through experiments, as well as their own comments about it. They can perform operations on the information they gather (establishing links between chunks of information by means of structuring relationships; storing the material according to multiple categories). The system encourages recursive movement throughout the modules, since inquiry proceeds as an opportunistic, revisionary task rather than a strictly topdown, linear one (Hawkins et al., in press; Mawby, 1986; Rescher, 1982). Students, for example, are encouraged to examine and revise their questions as they proceed in taking and linking notes.

(3) A "Schemes" module provides organizing supports for juxtaposing and analyzing one's own ideas with respect to new material that has been collected in pursuit of a solution to the inquiry problem. The supports are both topological (where students can build models of a phenomenon or a representation of the relationships among ingredients for problem solution), and linear (where students are encouraged to build and criticize arguments for a particular proposed problem solution). This module is designed to help students to juxtapose their ideas, those of others, and observational or experimental evidence, in order to build a new integrative conceptual scheme or to recognize new directions for continuing their inquiry.

(4) A "Patterns" module provides simple quantitative tools for analysis of data in the form of graphs and tables, and offers structured supports for finding trends in these data representations. This module embodies the strategy of helping students to interpret and use quantitative information in relation to their qualitative questions and understanding.

Overall, the INQUIRE software system is designed to structure the inquiry task in such a way that students are provided with tools that encourage them to examine their own and others' ideas, to establish and trace relationships among concepts, evidence and problems, and to recognize that this process is an interpretative and recursive one. The system is intended to be general purpose for science inquiry so that teachers and students can explore not only traditional science curriculum topics, but problem regions of their own devising. Problem sets are also being developed for research purposes to determine whether the process supports INQUIRE offers help students to develop their own explanations in ways that allow them to recognize the efficiency and utility of the explanations of canonical science. 


\section{Dynamic Support}

It has been repeatedly shown that students have difficulty managing the part-activities of complex information management or problem-solving tasks (e.g., Brown, Bransford, Ferrara, \& Campione, 1983). Because features of the technology can structurally support student accomplishment of the subtasks of science inquiry, students can participate in the whole task of science inquiry without necessarily having to first master all subskills. For example, with respect to information management, the system is designed to keep track of material for students by prompting them to supply source information (text or laboratory parameters) and automatically indexing and storing it. Keyword searches are automatically provided, and students are supported in developing their own structures for sorting information. Students can establish links among materials and then easily collect and browse the material they have thus categorized. They can readily try out different models for a solution that might represent, for example, different perspectives. The system also provides supports for the difficult processes of constructing and interpreting quantitative representations.

\section{Classroom Science Learning}

As noted above, it is difficult to conduct the sort of inquiry learning outlined here in classrooms, although several recent texts do help make cognitive science research findings on children's conceptions more accessible to science teachers (Driver, Guensem, \& Tiberghien, 1985; West \& Pines, 1985). Management of such individualized exploration is difficult, and the mere time required of teachers to understand the "natural" explanations students bring to empirical phenomena can make such interpretive activity prohibitive. The system is designed to take seriously some of these issues by extending the organizational tools for inquiry instruction available to the teacher.

First, we speculate that there is value in examining common assumptions about "products" expected of students' learning in science classrooms. Often, science assignments take the form of completed essays, papers, lab reports, or written responses to textbook questions. We have found that many students rush to write, with little reflection or inquiry; they often do not integrate information they may read with a question or problem they are ostensibly investigating (Hawkins, Mawby, \& Ghitman, in press). We propose teachers recognize the importance of intermediate products, prior to the writing of a well-structured essay or problem "answer," as evidence of the development of scientific understanding. A student's refinement of questions or problems, or the recognition of new ones, construction of models of phenomena or argument structures, oral reports of ideas, should all be considered as valued products in science education.

Second, the INQUIRE system can support individual or group investigation of problems or questions. It is designed to be not a tool that focusses on individual-computer interaction, but to work as a partner with teachers and students. While supporting work by one or more students, it may help teachers to "diagnose" the reasoning and foundations of student explanations because 
of the detailed traces the system records of their inquiry processes. Another feature allows teachers and other students to leave comments about the inquiry work as it proceeds. By helping to reveal the process of inquiry and exploration on the part of a student, teachers may be able to more effectively intervene in encouraging students to develop their explanations or problem ideas.

Third, the system is seen not as a singular response to the difficulties of science education, but as a part of a pluralistic approach to helping students to practice features of scientific interpretation, and to reflect on and confront their prior understandings and explanations that sufficed in precision for everyday thinking. Careful and sequenced presentation of scientific ideas and materials in relation to student inquiries will be essential complements to instructional work with INQUIRE. But it would take far more seriously than it does today the state of a student's understandings and forms of explanations of problem phenomena. In interaction with carefully supported inquiry, students may be led to recognize the beauty of encompassing scientific ideas, and the value of the explanatory standards of science communities. Inviting students to develop and investigate problems of interest to them takes seriously the need to engage learners in their own terms, and offers a window on the generative power of scientific inquiry practices. The acquisition of new knowledge and initiation into the "cultures" of science can be fun, not least because of the exhilaration of discovery often reported by scientists (e.g., John-Steiner, 1985; Polanyi, 1962). Finally:

"Let us recognize that the opposite of understanding is not ignorance or simply 'not knowing.' To understand something is, first, to give up some other way of conceiving it. . . . The child will make what he learns his own, will fit his discovery into the interior world of culture that he creates for himself. Equally important, discovery and the sense of confidence it provides is the proper reward for learning. It is a reward that, moreover, strengthens the very process that is at the heart of education-disciplined inquiry." (Bruner, 1962, p. 123-4).

Our hope is that an explicit recognition of the culture-bridging activities required for scientific understanding, supported by new technologies, may make such disciplined inquiry an integral feature of science education.

\section{Acknowledgments}

Ordership of authors was determined arbitrarily since this is a joint collaborative effort. Support for the research and development activities of the Inquire Project is provided by National Science Foundation Grant No. MDR-8550339 to the two authors. We would also like to thank Laura Martin for discussions of the cross-cultural nature of science learning.

\section{References}

Applebee, A. N., \& Langer, J. A. (1983). Instructional scaffolding: reading and writing as natural language activities. Language Arts, 60, 168-175.

Bernstein, R. J. (1983). Beyond objectivism and relativism: Science, hermeneutics, and praxis. Philadelphia: University of Pennsylvania Press. 
Bernstein, R. J. (1986). The question of moral and social development. In L. Cirillo \& S. Wapner (Eds.), Value presuppositions in theories of human development. Hillsdale, NJ: Erlbaum (pp. 1-12).

Black, M. (1954). The definition of scientific method. In M. Black (Ed.), Problems of analysis. Ithaca, NY: Cornell University Press.

Bredderman, T. (1983). Effects of activity-based elementary science on student outcomes: A quantitative synthesis. Review of Educational Research, 53, 499-518.

Brown, A. L., Bransford, J. D., Ferrara, R. A., \& Campione, J. C. (1983). Learning, remembering, and understanding. In J. H. Flavell \& E. M. Markman (Eds.), Handbook of child psychology (4th ed.), Vol. 3. Cognitive development. New York: Wiley \& Sons.

Bruner, J. S. (1962). On knowing: Essays for the left hand. Cambridge, MA: Harvard University Press.

Bullock, M., Gelman, R., \& Baillargeon, R. (1982). The development of causal reasoning. In J. Friedman (Ed.), The developmental psychology of time. New York: Academic Press.

Carey, S. (1985). Conceptual change in childhood. Cambridge, MA: MIT Press/Bradford Books.

Chaiklin, S. (1986). Novice physical-science problem-solving. Paper presented at the Bank Street College Conference on The Psychology of Physics Problem Solving: Theory and Practice. July 1986, New York, NY.

Clement, J. (1982). Students' preconceptions in introductory mechanics. American Journal of Physics, 50(1), 66-71.

Clement, J. (1986, August). Methods for evaluating the validity of hypothesized analogies. Proceedings of the Annual Meeting of the Cognitive Science Society. Amherst, MA (a).

Clement, J. (1986, July). Misconceptions in mechanics and an attempt to remediate them: The use of analogies and anchoring intuitions. Paper presented at the Bank Street College Conference on The Psychology of Physics Problem Solving: Theory and Practice, July 1986, New York, NY. (b).

Collins, A. (1986). A multiple-model theory of how people understand the physical world. Paper presented at the Bank Street College Conference on The Psychology of Physics Problem Solving: Theory and Practice, July 1986, New York, NY.

Dewey, J. (1933). How we think. Boston: Heath.

diSessa, A. (1982). Unlearning Aristotelian physics: A study of knowledgebased learning. Cognitive Science, 6, 37-75.

diSessa, A. A. (1983). Phenomenology and the evolution of intuition. In D. Gentner \& A. Stevens (Eds.), Mental models (pp. 15-33). Hillsdale, NJ: Erlbaum.

diSessa, A. A. (1986). Notes on a model of novice problem-solving. Paper presented at the Bank Street College Conference on The Psychology of Physics Problem Solving: Theory and Practice, July 1986, New York, NY. (a).

diSessa, A. A. (1986). Notes on the future of programming: Breaking the utility barrier. In D. A. Norman \& S. W. Draper (Eds.), User-centered system design. Hillsdale, NJ: Erlbaum, pp. 125-152. (b).

diSessa, A. (in press). Knowledge in pieces. In G. Forman (Ed.), Constructivism in the computer age. Hillsdale, NJ: Erlbaum. 
Driver, R., Guense, E., \& Tiberghien, A. (1985). Children's ideas in science. Milton Keynes, England: Open University Press.

Duschl, R. A. (1985). Science education and philosophy of science: Twenty-five years of mutually exclusive development. School Science and Mathematics, 85, 541-555.

Feyerabend, P. (1975). Against Method. New York: Schocken.

Feyerabend, P. (1978). Science in a free society. London: New Left Books.

Foucalt, M. (1980). Truth and power. In C. Gordon (Ed.), Power/knowledge. New York: Pantheon Books.

Gadamer, H. G. (1981). Reason in the age of science. Cambridge, MA: MIT Press.

Geertz, C. (1973). The interpretation of cultures: Selected essays. New York: Basic Books.

Geertz, C. (1983). Local knowledge. New York: Basic Books.

Gelman, R., Spelke, E. S., \& Meck, E. (1983). What preschoolers know about animate and inanimate objects. In D. Rogers \& J. A. Sloboda (Eds.), The acquisition of symbolic skills. London: Plenum.

Glynn, S. M., Britton, B. K., Muth, K. D., \& Dogan, N. (1982). Writing and revising persuasive documents: Cognitive demands. Journal of Educational Psychology, 74, 557-567.

Goodfield, J. (1982). An imagined world: A story of scientific discovery. New York: Harper \& Row.

Habermas, J. (1981). Theorie des kommunikativen handelns. Frankfurt: Suhrkamp Verlag.

Hacking, I. (1985). Styles of scientific reasoning. In J. Rajchman \& C. West (Eds.), Post-analytic philosophy. New York: Columbia University Press.

Halloun, I. A., \& Hestenes, D. (1985). The initial knowledge state of college physics students. American Journal of Physics, 53(11), 1043-1055.

Hawkins, J., Mawby, R., \& Ghitman, M. (in press). Practices of novices and experts in critical inquiry. In R. D. Pea \& K. Sheingold (Ed.), Mirrors of minds: Patterns of experience in educational computing. Norwood, NJ: Ablex.

Herron, M. D. (1971). The nature of scientific inquiry. School Review, 79, 171-212.

Hood, L., \& Bloom, L. (1979). What, when and how about why: A longitudinal study of early expressions of causality. Monographs of the Society for Research in Child Development 44 (Serial No. 181, No. 6).

Jackson, P. W. (1983, Spring). The reform of science education: A cautionary tale. Daedulus, 112(2), 143-166.

John-Steiner, V. (1985). Notebooks of the mind. Cambridge, MA: Harvard University Press.

Knorr-Cetina, K. D. (1981). The manufacture of knowledge. New York: Pergammon Press.

Kuhn, T. S. (1962). The structure of scientific revolutions. Princeton, NJ: Princeton University Press.

Kuhn, T. S. (1977). The essential tension: Selected studies in scientific tradition and change. Chicago: University of Chicago Press.

Laboratory of Comparative Human Cognition (1983). Culture and cognitive development. In P. H. Mussen (Ed.), Handbook of child psychology (4th ed.), Vol. 1. History, theory, and methods. New York: Wiley \& Sons. 
Lakatos, I. (1976). Proofs and refutations: The logic of mathematical discovery. Cambridge: Cambridge University Press.

Lave, J. (1986). Arithmetic practice and cognitive theory. New York: Cambridge University Press.

Lave, J., Murtaugh, M., \& de la Rocha, O. (1984). The dialectics of arithmetic in grocery shopping. In B. Rogoff \& J. Lave (Eds.), Everyday cognition: It development in social context. Cambridge, MA: Harvard University Press.

Linn, M. C. (1983). Content, context, and process in adolescent reasoning. Journal of Early Adolescence, 3, 63-82.

MacIntyre, A. (1981). After virtue. Notre Dame: University of Notre Dame Press.

Mawby, R. (1986). Questioning in inquiry: A microdevelopmental analysis. Unpublished doctoral dissertation, Clark University, Department of Psychology.

McDermott, L. (1984). Research on conceptual understanding in mechanics. Physics Today, 37(7), 24-32.

Miyata, Y., \& Norman, D. A. (1986). Psychological issues in support of multiple activities. In D. A. Norman \& S. W. Draper (Eds.), User-centered system design. Hillsdale, NJ: Erlbaum, pp. 265-284.

Nelson, K., \& Gruendel, J. (1981). Generalized event representations: Basic building blocks of cognitive development. In M. E. Lambe \& A. L. Brown (Eds.), Advances in developmental psychology. Vol. 1, pp. 131-158. Hillsdale, NJ: Erlbaum.

Norman, D. A. (1986). Cognitive engineering. In D. A. Norman \& S. W. Draper (Eds.), User-centered system design. Hillsdale, NJ: Erlbaum, pp. 3161.

Palincsar, A. S., \& Brown, A. L. (1984). Reciprocal teaching of comprehension-fostering and comprehension-monitoring activities. Cognition and Instruction, 1(2), 117-175.

Pea, R. D. (1985). Beyond amplification: Using the computer to reorganize human mental functioning. Educational Psychologist, 20(4), 167-182.

Pepper, S. (1942). World hypotheses. Berkeley, CA: University of California Press.

Piaget, J. (1971). Biology and knowledge: An essay on the relations between organic regulations and cognitive processes. Chicago: University of Chicago Press.

Polanyi, M. (1962). Personal knowledge. New York: Harper.

Posner, G. J., Strike, K. A., Hewson, P. W., \& Gertzog, W. A. (1982). Accommodation of a scientific conception: Toward a theory of conceptual change. Science Education, 66(2), 211-227.

Rescher, N. (1982). Empirical inquiry. Totowa, NJ: Rowman and Littlefield.

Rorty, R. (1979). Philosophy and the mirror of nature. Princeton: Princeton University Press.

Rorty, R. (1982). Pragmatism, relativism, and irrationalism. In Consequences of pragmatism. Minneapolis: University of Minnesota Press.

Ryle, G. (1954). The world of science and the everyday world. In G. Ryle, Dilemmas. Cambridge: Cambridge University Press, pp. 68-81. 
Scardamalia, M., \& Bereiter, C. (1985). Research on written composition. In M. C. Wittrock (Ed.), Handbook of research on teaching. (3rd ed.). New York: Macmillan (pp. 778-803).

Schoenfeld, A. (1985). Mathematical problem solving. New York: Academic Press.

Schwab, J. (1960). What do scientists do? Behavioral Science, 5, 1-27.

Shultz, T. R. (1982). Rules of causal attribution. Monographs of the Society for Research in Child Development 47 (1, Serial No. 194).

Shymansky, J., Kyle, W., \& Alport, J. (1983). The effects of new science curricula on student performance. Journal of Research in Science Teaching, 20, 387-404.

Simon, H. A. (1981). Sciences of the artificial (2nd ed.). Cambridge, MA: MIT Press.

Snyder, S. S., \& Feldman, D. H. (1977). Internal and external influences on cognitive developmental change. Child Development, 48, 937-943.

Stavy, R., \& Berkowitz, B. (1980). Cognitive conflict as a basis for teaching quantitative aspects of the concept of temperature. Science Education, 64, 679-692.

Stevens, A., \& Collins, A. (1980). Multiple conceptual models of a complex system. In R. E. Snow, P. A. Federico, \& W. E. Montague (Eds.), Aptitude, learning and instruction (Vol. 2, pp. 177-197). Hillsdale, NJ: Erlbaum.

Strauss, S. (in press). Educational-developmental psychology and school learning. In L. Liben \& D. H. Feldman (Eds.), Development and learning: Convergence or conflict? Hillsdale, NJ: Erlbaum.

Strauss, S., \& Ilan, J. (1977). Length conservation and the speech concept: Organizational disequilibrium training between concepts. Journal of Educational Psychology, 67, 47-477.

Taylor, C. (1980). Understanding in human science. Review of Metaphysics, 34, 39-48.

Toulmin, S. E. (1972). Human understanding. Princeton: Princeton University Press.

Toulmin, S. E. (1982). The construal of reality: Criticism in modern and postmodern science. Critical Inquiry, 9, 93-111.

Vygotsky, L. S. (1962). Thought and language. Cambridge, MA: MIT Press.

Vygotsky, L. S. (1978). Mind in society. M. Cole, V. John-Steiner, S. Scribner, \& E. Souberman (Eds.). Cambridge, MA: Harvard University Press.

West, L. H., \& Pines, A. L. (Eds.), (1985). Cognitive structure and conceptual change. New York: Academic Press.

White, B. (1983). Sources of difficulty in understanding Newtonian dynamics. Cognitive Science, 7, 41.

Manuscript accepted December 1, 1986 